\title{
Na Casa e na Rua: Cenas dos Moradores de Serviços Residenciais Terapêuticos
}

\author{
Paula Andréa Massa ${ }^{1}$ \\ ${ }^{1}$ Universidade Federal de São Paulo, SP, Brasil.
}

\author{
Maria Inês Badaró Moreira ${ }^{1}$ \\ ${ }^{1}$ Universidade Federal de São Paulo, SP, Brasil.
}

\begin{abstract}
Resumo: O objetivo deste estudo foi compreender o agenciamento social da loucura, na perspectiva da desinstitucionalização, por meio da observação participante de cenas do cotidiano de moradores deServiços ResidenciaisTerapêuticos (SRT). Trata-se de uma pesquisa social em saúde, de abordagem qualitativa, com inspirações etnográficas e orientação fenomenológica. Os dez participantes são moradores de dois SRT de uma cidade localizada na região Sudeste do Brasil. Têm 60 anos em média, são ex-moradores de hospitais psiquiátricos e metade é do sexo feminino. Os resultados são 12 cenas de convivência no espaço coletivo da casa, da circulação social nas ruas do bairro e do acesso a serviços comerciais, de saúde e cultura. Observou-se que os participantes vivenciam, cotidianamente e de diferentes formas, a apropriação ou reapropriação do corpo, da casa e da rua. Trata-se de um processo de vivificação do eu que pode partir da expropriação de si e pode alcançar a incorporação, com relações de pertencimento a um corpo social. Concluiu-se que o poder aquisitivo e as construções sociais relacionadas aos corpos dos moradores no encontro com diferentes atores são circunstâncias que podem interferir nesse processo. As conversações de reautoria, práticas narrativas baseadas no construcionismo social, e as práticas e táticas cotidianas, na perspectiva de Michel de Certeau, são teorias que contribuem para a compreensão e instrumentalização do agenciamento social dos moradores de SRT nos espaços públicos e privados.
\end{abstract}

Palavras-chave: Desinstitucionalização, Saúde Mental, Serviço Residencial Terapêutico, Reforma Psiquiátrica.

\section{At Home and on the Street: The Scene of Residents of Therapeutic Residential Care}

\begin{abstract}
This study aimed to understand the social management of madness from the perspective of deinstitutionalization by means of participant observation of daily life scenes of residents at Therapeutic Residential Care (TRC). This is a qualitative social health research with ethnographic inspirations and phenomenological orientation. Participants consisted of ten former residents of a psychiatric hospitals, half of whom are female and with mean age of 60 years old, current residing in a TRC of a city located in a Southeast region of Brazil. The results indicate 12 scenes of coexistence within the collective space of the houses, social circulation in the neighborhood streets, and access to commercial, health, and cultural services. Daily and in different ways, the participants experience the appropriation or reappropriation of body, house, and street. In this sense, these scenes comprise a process of vivification of the self that can depart from self-expropriation and reach incorporation, establishing relations of social belonging. These findings show that purchasing power and social constructions regarding residents' body in the encounter with different actors are circumstances that can interfere in this process. The re-authoring conversations, narrative practices based on social constructionism, and everyday practices and tactics, from Certeau's perspective, are theories that help understanding and instrumentalizing the social agency of residents of TRC in public and private spaces.
\end{abstract}

Keywords: Deinstitutionalization, Mental health, Therapeutic Residential Care, Psychiatric Reform. 


\title{
En la Casa y en la Calle: Escenas de los Residentes de Servicios Residenciales Terapéuticos
}

\begin{abstract}
Resumen: El objetivo de este estudio fue comprender el agenciamiento social de la locura desde la perspectiva de la desinstitucionalización, por medio de la observación participante de escenas del cotidiano de moradores de Servicios Residenciales Terapéuticos (SRT). Esta es una investigación social en salud, de abordaje cualitativo, con inspiraciones etnográficas y orientación fenomenológica. Los diez participantes son residentes dos SRT de una ciudad en sudeste de Brasil. Tienen como promedio 60 años de edad, son ex residentes de hospitales psiquiátricos y la mitad son mujeres. Los resultados son doce escenas de convivencia en el espacio colectivo de la casa, de la circulación social en las calles del barrio y del acceso a servicios comerciales, de salud y cultura. Se observó que los participantes vivencian, cotidianamente y de diferentes formas, la apropiación o reapropiación del cuerpo, de la casa y de la calle. Se trata de un proceso de vivificación del yo que puede partir de la expropiación de sí y puede alcanzar la incorporación, con relaciones de pertenencia, a un cuerpo social. Se concluyó que el poder adquisitivo y las construcciones sociales relacionadas con los cuerpos de los residentes en el encuentro con diferentes actores pueden interferir en ese proceso. Las conversaciones de re-autoría, prácticas narrativas basadas en el construccionismo social, y las prácticas y tácticas cotidianas, en la perspectiva de Certeau, son teorías que contribuyen a la comprensión e instrumentalización del agenciamiento social de los moradores de Servicios Residenciales Terapéuticos en los espacios públicos y privados.
\end{abstract}

Palabras clave: Desinstitucionalización, Salud Mental, Servicio Residencial Terapéutico, Reforma Psiquiátrica.

\section{Introdução}

$\mathrm{Na}$ contemporaneidade, a psiquiatria passou a ser compreendida como um campo de conhecimento responsável pelo agenciamento da loucura, recém-batizada de doença mental. A internação e o isolamento social em hospitais psiquiátricos foram uma proposição do psiquiatra Philippe Pinel, no século XVIII, como parte do tratamento moral. Ainda no final do século XIX, os propositores deste modelo observaram a impotência terapêutica e a superlotação dos hospitais psiquiátricos e questionaram se seria possível oferecer um tratamento individualizado quando cabia a um médico o cuidado de 400 a 500 pacientes. A partir da década de 1940, diversos movimentos reformistas nos Estados Unidos e na Europa propuseram a ampliação para uma rede de cuidados com serviços comunitários como uma alternativa a esse modelo hospitalocêntrico (Desviat, 1999).

A Reforma Psiquiátrica Brasileira, iniciada há mais de 30 anos, foi influenciada pelos movimentos reformistas norte-americano e francês, mas se inspirou na proposta democrática italiana. Esse movi- mento foi pioneiro ao compreender a psiquiatria como instituição e um conjunto de aparatos científicos, legislativos, administrativos e códigos de referência cultural. O psiquiatra Franco Basaglia, um de seus representantes, propôs a desinstitucionalização como uma mudança de paradigma, uma ruptura no modo de entender o sofrimento psíquico e, consequentemente, o seu cuidado (Rotteli \& Nicácio, 2001). Essa transformação radical compreende que o sofrimento psíquico se constitui na vida concreta das pessoas e nas relações sociais, de forma que o foco passa a ser a pessoa em sua complexidade, e não a doença. Nessa perspectiva, o objetivo não é a eliminação de sintomas, mas a produção de vida com sentido, buscando o protagonismo e a emancipação para fazer escolhas e tomar decisões (Basaglia, 2010).

Nicácio (2003) divide a trajetória brasileira em três vias. A via alternativa ocorre pela denúncia dos trabalhadores de saúde mental das situações de maus-tratos e negligências vividas nos hospitais psiquiátricos. A via sanitarista, orientada por ideias pre- 
ventivistas e comunitárias, culmina na proposição da Lei no 10.216 (2001), que reorienta o modelo assistencial e garante os direitos das pessoas com transtornos mentais. A via da desinstitucionalização é marcada pelo envolvimento de usuários e familiares, além da produção de conhecimento para inovação no cuidado com o protagonismo dos usuários.

Em busca da consolidação dessa reforma, foi criada a Rede de Atenção Psicossocial (Raps), da qual um dos componentes é a "Estratégia de desinstitucionalização", e os Serviços Residenciais Terapêuticos (SRT), que representam um de seus pontos de atenção (Portaria no 3.088, 2013). Os SRT são casas para egressos de internações psiquiátricas de longa permanência, localizadas em espaços urbanos e financiadas por meio da realocação do recurso público. Os valores gastos com a manutenção de hospitais psiquiátricos passaram a custear a abertura e manutenção dos SRT após o fechamento dos hospitais (Portaria no 106, 2000).

Furtado (2006) identificou que existe um descompasso entre o descredenciamento dos leitos em hospitais psiquiátricos e a abertura de novos SRT. Desde a década de 1990, 60 mil leitos em hospitais psiquiátricos foram fechados (Ministério da Saúde, 2016). No estado de São Paulo, dois censos psicossociais revelaram que, entre 2008 e 2014, houve mais leitos descredenciados por óbito dos moradores de hospitais psiquiátricos do que por transferência para um SRT (Barros \& Bichaff, 2008; Cayres, Penin, Ribeiro, Costa, \& Nagafuchi, 2015). Segundo o panorama apresentado pelo Ministério da Saúde (2017), existem 489 SRT habilitados no cenário brasileiro.

O Ministério da Saúde (2016) reconhece que existe uma dificuldade no avanço e traz como principal obstáculo para a expansão deste serviço as mudanças políticas, socioculturais e técnicas relacionadas ao processo de desinstitucionalização do modo como fora proposto por Basaglia. O investimento financeiro da instância federal para a ampliação da rede substitutiva não é acompanhado pelas esferas estaduais e municipais, o que traz baixa resolutividade (Pitta, 2011). Vasconcelos (2012) nomeia esse processo de bloqueio estrutural e explica que o subfinanciamento e sucateamento das políticas sociais universais são consequências da crise econômica detonada pelo capitalismo neoliberal. Para que essas políticas funcionem como um contrapeso bem-sucedido, recomenda a sistematização de uma política de estado com base na conjuntura política, econômica e social.
Ao refletir sobre a desinstitucionalização, Tenório (2002) identifica dois planos: "um mais estritamente técnico, da rede e das práticas de cuidado, e outro mais amplo, dito cultural” (p. 55). Conclui que ambos são faces do agenciamento social da loucura, porque “mesmo a ação técnica mais especifica está animada pela questão de como agenciar o pertencimento social do louco ... positivamente" (Tenório, 2002, p. 55).

$\mathrm{O}$ agenciamento social pode ocorrer por meio do empréstimo do poder contratual, que é "o valor previamente atribuído para cada indivíduo dentro do campo social no intercâmbio e tem três dimensões: bens, mensagens e afetos" (Kinoshita, 2001, p. 55). O empréstimo do poder contratual significa "utilizar o prestígio, a delegação social, o saber reconhecido pela sociedade aos profissionais, para possibilitar relações e experiências renovadas aos usuários" (Barros, Oliveira, \& Silva, 2007, p. 817). É uma mediação que busca substituir a relação de tutela pela de contrato, e o resultado esperado é um sujeito com direitos em busca de autonomia e emancipação.

Sobre o plano cultural, Tenório (2002) contemporiza que a loucura é um problema para o corpo social, pois o dissonante é justamente o que incomoda. $\mathrm{O}$ trabalho, então, é de reconhecer e agenciar essa tensão, movimentando-se para além do que cabe nas políticas sociais do Estado, em direção à vida em uma sociedade sem manicômios e inclusiva. A partir dessa contextualização, o objetivo deste estudo foi compreender o agenciamento social da loucura no cuidado em liberdade a partir de cenas do cotidiano de moradores de SRT.

\section{Método}

Esta pesquisa se insere no campo dos estudos sociais em saúde, tem abordagem qualitativa e a fenomenologia como orientação filosófica (Minayo, 2008). Spink (2007) sugere estudos que analisam quais atividades cotidianas devem desenvolver compreensões compartilhadas, com o intuito de torná-las visíveis e relatáveis.

Para a coleta de dados, utilizou-se a observação participante, com inspirações etnográficas. Para Magnani (2009), a observação participante é um instrumento da etnografia que pode ser utilizado quando há um envolvimento mais profundo no cotidiano dos participantes para ajudar na busca por uma ordenação e interpretação do que se observa, para além da mera descrição e coleta de dados. A observação participante dos moradores foi feita no trajeto entre a 
residência terapêutica e diferentes locais da cidade. Também foram observadas situações não planejadas ocorridas durante a investigação.

Os SRT referidos neste estudo estão localizados em uma cidade de médio porte da Grande São Paulo. A partir do fechamento do hospital psiquiátrico e desospitalização de seus moradores, o município ampliou a rede substitutiva para a atenção psicossocial, composta, entre outros pontos, por seis SRT. Cada casa conta com um suporte de nove acompanhantes terapêuticas ${ }^{1}$.

Três SRT foram selecionados pela coordenação municipal de saúde mental para participação na pesquisa. Dez moradores de duas residências aceitaram participar e assinaram o Termo de Consentimento Livre e Esclarecido. Esta pesquisa foi aprovada pelo Comitê de Ética da Universidade Federal de São Paulo, sob o parecer $n^{\circ} 1.727 .506 / 2016$, em concordância com a Resolução no 466/2012.

A observação participante foi registrada em diários de campo que foram a matéria-prima para a construção de cenas (Vaz, Silva, \& Campos, 2014). Foram selecionadas informações sobre interesses, escolhas e atitudes dos participantes; cenários - a casa, as ruas do bairro e os espaços públicos acessados; e das relações sociais estabelecidas. Nos encontros entre pesquisador e pesquisado, alguns participantes optaram por falar sobre fatos de sua história de vida e planos futuros. Essas informações foram consideradas na análise. Para a discussão dos achados, buscou-se um diálogo com teorias que contribuíssem para a compreensão do agenciamento social da loucura.

\section{Resultados e análise}

Metade das participantes é do sexo feminino e o grupo tem idade média de 60 anos (34-85 anos). Seis são da região Sudeste e quatro são do Nordeste do Brasil. A maioria tem ensino fundamental incompleto e uma das participantes é analfabeta. Todos passaram por internação psiquiátrica de longa permanência e recebem benefícios do Programa de Volta pra Casa (PVC) ou Benefício de Prestação Continuada da Assistência Social (BPC-Loas).

Os dados foram produzidos entre setembro de 2016 e janeiro de 2017 e subsidiaram a construção de 12 cenas (Tabela 1).

Tabela 1

Listagem dos locais e atividades realizadas por participante.

\begin{tabular}{|c|c|c|c|}
\hline $\begin{array}{c}\text { Tipo por função } \\
\text { principal }\end{array}$ & Local & Atividade & Participante \\
\hline \multirow{5}{*}{ Serviços de saúde } & \multirow{3}{*}{$\begin{array}{l}\text { Centro de Atenção } \\
\text { Psicossocial II } \\
\text { (Caps) }\end{array}$} & $\begin{array}{l}\text { Participar da confraternização de } \\
\text { final de ano }\end{array}$ & Todos \\
\hline & & $\begin{array}{l}\text { Participar do grupo de caminhada } \\
\text { e assembleia }\end{array}$ & Antônio \\
\hline & & $\begin{array}{c}\text { Participar do Movimento de } \\
\text { Alfabetização de Jovens Adultos } \\
\text { (Mova)* }\end{array}$ & $\begin{array}{l}\text { Vítor, Jesus, Patrícia e } \\
\text { Antônio }\end{array}$ \\
\hline & \multirow{2}{*}{$\begin{array}{l}\text { Unidade Básica de } \\
\text { Saúde (UBS) }\end{array}$} & Consultar com médica de família & Charlene \\
\hline & & Consultar com médica de família & Ana \\
\hline \multirow{5}{*}{$\begin{array}{l}\text { Estabelecimento } \\
\text { comercial }\end{array}$} & Supermercado & $\begin{array}{l}\text { Comprar itens para preparação do } \\
\text { almoço de confraternização }\end{array}$ & Ana \\
\hline & Feira & $\begin{array}{c}\text { Comprar verdura, frutas, legumes e } \\
\text { temperos }\end{array}$ & Ana e Patrícia \\
\hline & Rodoviária & Buscar uma familiar & Patrícia \\
\hline & Loja & Comprar roupa & Patrícia \\
\hline & Banco & Sacar benefício & Patrícia \\
\hline
\end{tabular}

${ }^{1}$ São cuidadores responsáveis por dar apoio aos moradores nas atividades de vida diária, higiene pessoal, preparo e consumo da alimentação, organização doméstica, uso das medicações, realização de compras, além de acompanhá-los em atividades externas de lazer e cultura, de acordo com a necessidade de cada morador (Secretaria Municipal de Saúde de São Bernardo do Campo, 2012). 
...continuação

\begin{tabular}{cccc}
\hline $\begin{array}{c}\text { Tipo por função } \\
\text { principal }\end{array}$ & Local & Atividade & Participante \\
\hline $\begin{array}{c}\text { Equipamentos sociais de } \\
\text { cultura e lazer }\end{array}$ & Igreja & Participar do culto & Charlene e Ana \\
& Pinacoteca** & Participar do Coletivo Traço*** & Maurício \\
\hline
\end{tabular}

Nota. *Projeto criado por Paulo Freire na década de 1980 para alfabetização de adultos; **Museu de artes visuais é um equipamento cultural vinculado ao governo estadual; ***Projeto de inclusão cultural, fruto de uma parceria entre o Caps, Nutrarte e a Pinacoteca do município.

Os locais acessados foram tipificados de acordo com sua função principal, e percebe-se que os estabelecimentos comerciais são os mais frequentados pelos moradores. Este dado mostra o impacto da existência e gestão de um recurso financeiro na socialização dos participantes, em consonância com os achados nos estudos revisados (Honorato \& Pinheiro, 2008; Lago, Machado, Vieira, \& Monteiro, 2014; Paulon, Resende, Knijnik, Oliveira, \& Abreu, 2007; Santos Junior \& Silveira, 2009; Sztajnberg \& Cavalcanti, 2010; Wachs, Jardim, Paulon, \& Resende, 2010). O poder de compra-ser consumidor - é uma vivência de um lugar de contratante, ainda passivo, como afirmou Basaglia (2010), e não ativo como seria considerado no lugar de produção.

Observou-se também que os moradores acessam, prioritariamente, serviços de saúde, principalmente o Caps e a UBS, expandindo a vida para a cidade em espaços de lazer, e recebem visitas dos familiares. Mais da metade dos participantes resgatou as relações familiares, o que confirma o que afirmou Basaglia (2010) sobre a doença ter um caráter acessório e secundário na determinação do tratamento. Nesse sentido, o que prevalece nessa escolha é o valor social e contratual daquele sujeito. Ser morador de hospital psiquiátrico é consequência da fragilidade ou de rompimento dos laços familiares; diferentemente disso, ser morador de SRT possibilitou o fortalecimento e a ampliação dos laços sociais.

No estudo sobre a vida subjetiva de internos de instituições totais, como os hospitais psiquiátricos, Goffman (2015) descreveu a mortificação do "eu" como um processo de desculturamento e destreinamento, fruto da anulação dos papéis antes exercidos e consequência da barreira imposta entre os internos e o mundo externo. Sobre a possibilidade de restabelecimento de papéis ao retorno da convivência social, o autor defendia que algumas perdas são irrecuperáveis.
É possível supor que, como ex-moradores de um hospital psiquiátrico, os participantes tenham vivenciado a transformação de uma realidade de mortificação do "eu" para uma inserção na cidade. Constatou-se que é possível a transformação entre ser reduzido a um objeto, expropriado, tutelado e com troca social zero para um lugar no corpo social, ou seja, com experiências de incorporação. Esse é um processo reverso do vivido como moradores de instituições totais e foi chamado de vivificação do "eu". As vivências de apropriação e reapropriação parecem se configurar como passos dados nesse caminhar.

Antes da análise desses achados, faz-se necessário esclarecer como os verbos "apropriar" e "incorporar" são utilizados neste estudo. O verbo apropriar tem vários significados, dos quais se destacam duas definições. Uma delas é quando se refere a tornar próprio, apossar-se, tornar seu uma coisa alheia, apoderar-se, e a outra definição é tornar ou ser adequado, conveniente a (Ferreira, 2014).

Ao receber o prefixo exe virar o substantivo "expropriação", passa a significar desapossar uma pessoa da titularidade de um bem ou de um direito (Ferreira, 2014), e é utilizado aqui para expressar como os ex-moradores de manicômios iniciam sua carreira após a desospitalização: expropriados de si, ou seja, desapossados por alguém de sua propriedade, seu próprio corpo, seu nome, sua história, seu destino. Esse processo pode ser consequência da mortificação do "eu" e ter início antes mesmo da internação, quando em suas relações sociais são considerados desarrazoados.

Em uma condição de poder contratual zero, "os bens dos loucos tornam-se suspeitos, as mensagens incompreensíveis, os afetos desnaturados, tornando praticamente impossível qualquer possibilidade de trocas" (Kinoshita, 2001, p. 55). É delegado ao Estado e seus representantes, por exemplo, 
os profissionais de saúde, o direito de se apropriar, se apossar, tornar sua uma coisa alheia, ou seja, o corpo, os desejos e as decisões deste louco, sob a justificativa de ser seu papel, apropriá-lo, torná-lo adequado e conveniente ao jogo social.

Em liberdade, em busca da vivificação do "eu", inicia-se um processo de reapropriação, apropriar-se de algo novamente, pegar de volta, tomar posse de si mesmo, ou até mesmo de apropriação como uma primeira experiência. Ocorre em várias instâncias, com o corpo, com o espaço privado e com o espaço público. É importante salientar que as apropriações se iniciam pelo que está dado, pelo já construído, mas existe uma singularidade que se expressa na criatividade, na capacidade e na flexibilidade de uso e nas atividades coletivas ou particulares do cotidiano. No encontro com o outro, no estabelecimento de relações, na exploração de sua maneira de fazer uso, a apropriação pode gerar subsídios que alimentem um novo projeto, uma construção, em busca de fazer parte do corpo social, incorporar-se.

O verbo "incorporar" é sinônimo para misturar, juntar, ligar; incluir; admitir como membro; formar parte; reunir-se a uma coletividade ou corpo (Ferreira, 2014). Pressupõe relação, construção, interação; assim, lança a novidade, então, de posse de si: reapropriando-se ou apropriando-se, buscam agregar vivências, experiências, identificar-se, incluir-se, pertencer a um coletivo, fazer parte de um corpo social. É preciso saber como esse corpo estabelece relações e conexões. Incorporação significa também como esse corpo é fronteira, é definido, é localizado, é ou não incorporado pelo outro. Os significados lhes são atribuídos, carregam saber, poder, consciência, identidade, simbolizam um modo de vida, uma cultura.

A pesquisa indica que houve a incorporação, a partir de uma vivência de expropriação, como exemplificam as histórias contadas pelos participantes, identificados a seguir com nomes fictícios. Ana abriu um processo jurídico em busca de ter seus direitos garantidos quanto ao pagamento de benefícios. Quando foi internada estava sem seus documentos. Seus registros foram feitos em nome do apelido que lhe foi dado pelos profissionais de saúde. Lucas Moura não tem conhecimento de sua origem, local e nome de seus pais. Procurou a cidade que consta em seus documentos, mas não existe no cartório o registro de nascimento. Adriana recebeu uma herança dos pais, uma casa, que está sob posse de seus primos e ela não tem acesso. É possível vislumbrar que ações de reapropriação podem ser identificadas a partir do reconhecimento de situações de expropriação que pode ser do nome, da história, do corpo, da origem, de um bem etc.

Alguns exemplos de reapropriação foram observados: Ana é reconhecida e respeitada pela acompanhante terapêutica por entender muito sobre cozinhar, e assim, orienta as compras no supermercado. Desse modo, se resgata uma competência que tinha quando trabalhava como cozinheira antes da internação. Maurício relata ter perdido a habilidade de desenhar, mas a partir de sua participação no Coletivo Traço, pôde se reapropriar do lugar de desenhista e descobrir que prefere desenhar com carvão, porque pode mostrar luz e sombra.

Para Patrícia, a apropriação de seu corpo, desejos e interesses não aconteceram antes da internação. Ela perdeu a mãe aos 6 anos, sofreu abuso sexual na adolescência, aos 16 trabalhou como cuidadora de um menino, casou-se aos 18, adoeceu após a primeira gravidez, teve uma segunda gravidez e foi internada. $\mathrm{Na}$ cena em que ela recebeu uma visita, esse enredo foi relatado por uma familiar sua, justificando a surpresa por Patrícia estar aprendendo a ler, escrever e cozinhar.

A apropriação do corpo é aspecto fundamental nesse processo em seus diferentes registros: biológico, social, sexual, jurídico etc. Foi possível observar no cotidiano dos participantes variados exemplos entendidos como retomada de poder em relação ao próprio corpo, uma reapropriação que se dá ao viver em uma SRT: beber água quando se tem sede, comer algo que lhe dá prazer, ter objetos próprios e de uso pessoal, fazer as unhas e tingir o cabelo em casa ou no salão, comprar e cozinhar os alimentos que serão consumidos, tomar dois banhos por dia, limpar a mesa e as cadeiras, cortar e refogar os legumes, temperar o arroz, assistir ao jogo de futebol e por isso dormir até mais tarde no dia seguinte e comer um biscoito de polvilho no ônibus.

O controle da própria aparência, o reconhecimento de sensações corporais e a descoberta de prazer nas atividades cotidianas são passos em direção à apropriação do corpo, no caminho da vivificação do "eu". Foi possível perceber que mais do que executar atividades cotidianas, poder escolher a forma como fazem é uma vivência de cuidado da saúde em liberdade.

\section{Discussão}

Abre-se um convite à reflexão sobre como é possível potencializar esse processo de vivificação do "eu". Para a discussão dos resultados, foi realizada uma inter- 
locução entre os achados e teorias que colaboram para a compreensão de práticas mais ou menos potentes para o agenciamento social dos moradores de SRT.

\section{O uso das práticas e táticas no cotidiano}

Na observação participante da convivência no espaço do SRT, percebeu-se que os moradores realizam práticas cotidianas, tais como comer, dormir, limpar, morar, cozinhar, passear, caminhar, desenhar, receber visitas, participar do grupo de orações, comprar. Certeau, Giard e Mayol (2016) propuseram uma concepção política do agir do homem comum, uma ciência prática do singular, que pode contribuir para a compreensão de como a possibilidade de realizar práticas cotidianas opera na vivificação do "eu".

Certeau (1998, p. 46) definiu as maneiras de fazer de cada um como "uma inventidade artesanal... uma combinação única de elementos ... um patchwork do cotidiano". Para exemplificar essa ligação entre a arte de fazer e a arte de viver, o autor descreve invenções cotidianas de um dos sujeitos de sua pesquisa que se assemelham ao cotidiano observado neste estudo, as "pequeninas alegrias":

Ele organizou os seus dias de tal modo que eles compõem um encadeamento harmonioso de pequeninas alegrias . . .. Uma xícara de café e uma fatia de pão com manteiga, um prato de ervilhas verdes, a leitura do jornal ..., mil satisfações tranquilas que o esperam em cada esquina da vida, ... são para ele tão necessárias como o ar que respira (Certeau, 1998, p. 32).

Segundo Schmidt (2009), há nessas passagens uma clara defesa de que as práticas cotidianas precisam ser associadas a outros modos de funcionamento da realidade social, por exemplo, seus sistemas econômicos e suas representações. Entretanto, o autor entende que cada indivíduo é um lócus, no qual uma pluralidade de determinações relacionais interage. A ênfase recai nos procedimentos microscópicos, ou seja, nas práticas cotidianas que se tornam resistências que os fracos conseguem operar na ordem estabelecida pelos fortes.

Certeau et al. (2016) definem tática como um artifício utilizado pelo fraco que, com astúcia, reconhece momentos oportunos e os transformam em ocasiões em que pode ter ganhos. É como se age quando sub- metido a uma lógica dominante. Estar no SRT é estar em uma casa, é estar na cidade, onde existem relações de força, uma ordem social estabelecida que oprime. Morar em um serviço de saúde traz uma imposição sobre como viver, contudo, estar em uma casa no bairro aumenta a chance do uso das táticas para uma apropriação criativa e, por vezes, subversiva dessa realidade que lhes é imposta nas relações sociais. Assim, pessoas antes julgadas como incapazes de conviver socialmente, taticamente, estão comumente criando suas trajetórias pelas ruas do bairro. Acredita-se que a subversão da ideia dominante de impossibilidade de agenciamento social da loucura ocorra quando o espaço público é utilizado por esses moradores.

Em duas cenas, observou-se que existe uma diversidade na maneira de habitar e na intensidade do uso do espaço urbano. Em uma cena, todos foram à festa no Caps, mas Antônio foi sozinho antes dos demais para ajudar na organização. Ao lado das acompanhantes terapêuticas, Charlene foi a pé levando enfeites confeccionados pelas moradoras de sua SRT; Vítor, Jesus e Lucas Moura levaram os frangos assados para o almoço; e Patrícia, Adriana e Elisabete foram no carro cedido pelo Caps. Ana foi à festa sozinha após sua atividade na igreja. São "diferentes passos em um mesmo cenário" (Certeau, 1998, p. 109). Percebeu-se que, mesmo quando os lugares acessados são os mesmos, existe uma variação no trajeto, resultado de escolhas.

As trajetórias podem ser compreendidas como unidades de uma sucessão de pontos percorridos, inaugurados a partir do local de habitação, e que se tornam marcas criadas por si mesmo, impostas ao espaço urbano. É neste espaço que se dá a relação entre as pessoas. Sair de casa, andar pela rua é efetuar um ato cultural, pois inscreve o habitante em uma rede de sinais que lhe são preexistentes. Estar no bairro gera um conhecimento dos lugares, das relações de vizinhança, e pode se tornar um lugar de reconhecimento e de pertencimento (Certeau et al., 2016).

Na segunda cena, Jesus, Antônio e Vítor se deslocam entre o Caps e o SRT para ir e vir de uma atividade de alfabetização de adultos, trajeto feito de segunda a quinta-feira, no mesmo horário. Observou-se que as vizinhas lavavam o quintal quando os participantes passaram por elas e não houve demonstração do hábito de se cumprimentarem.

Essa cena nos mostra que para o agenciamento social e estabelecimento de laços com a vizinhança, mais do que escolher trajetos, é necessário reconhe- 
cer a prática do bairro, definida por Certeau et al (2016) como uma convenção coletiva tácita legível por meio de códigos de linguagem e de comportamento. No convívio com a vizinhança, pode-se afirmar que existe um jogo de exclusão daqueles que não são e nem fazem o esperado. É um contrato que obriga cada um a se encaixar na vida do coletivo no público.

Mais do que desempenhar papéis, o objetivo é trazer sua própria voz para a cena da vida, uma via para a reformulação das representações sociais da loucura e o avanço na garantia da cidadania. A incorporação depende do protagonismo, o que foi observado nas cenas de Maurício, Antônio e Ana. Eles mostraram que têm laços e relações de pertencimento com a comunidade em que vivem: Ana faz parte do grupo de orações da igreja e do grupo de alongamento da UBS; Antônio realiza caminhada em grupo e Maurício frequenta o Coletivo Traço da Pinacoteca. Além de participarem como membros de grupos, vivenciam a incorporação ao novo grupo que passaram a compor. Assumem, inclusive, a responsabilidade de serem acompanhantes de outros moradores. A pluralidade e circulação de papéis é uma estratégia de sustentação da incorporação, aquilo que vem e se mistura, passa a ser parte de mim e passa a ter de mim. Uma das características fundamentais da proposta de Basaglia (2010): mais do que o direito de se perceber, é a possibilidade de se realizar.

\section{Entrelaçando vozes e corpos, na casa e na rua}

Estudos sobre os SRT que tiveram como participantes os moradores e profissionais que lá trabalham reconhecem que os cenários são diversos e apontam para a existência dos muros manicomiais, que deixam de ser concretos e passam para o plano das relações, colocando barreiras no fazer, ir e vir para pessoas que viveram internações de longa data (Mângia \& Ricci, 2011; Marcos, 2004; Matos \& Moreira, 2013; Sztajnberg \& Cavalcanti, 2010). Por outro lado, Moreira \& Andrade (2010, p. 362) apontaram que é "possível considerar a cidade como espaço de trocas capaz de produzir outras formas de estar na vida, capaz de possibilitar relações de homens como iguais, não hierarquizados". Os obstáculos vividos pelos moradores desses equipamentos se assemelham aos obstáculos sociais, que ficam mais agravados em tempos de precarização das políticas sociais, como vivemos atualmente (Moreira \& Andrade, 2007). Os muros manicomiais podem ser também entendidos como barreiras que separam de acordo com a classe social, gênero e orientação sexual.

Fazer uma análise a partir de um recorte de gênero, por exemplo, propiciou a identificação de algumas vivências que podem ser consideradas com menor potência para a vivificação do "eu". Em uma das residências, onde moram apenas homens, existem regras que ordenam os modos de fazer em relação às atividades domésticas. Os moradores aguardam enquanto as acompanhantes terapêuticas cozinham. No outro SRT, habitado por mulheres, há mais incentivo para que as moradoras se envolvam em atividades de limpeza e cozinha, compras na feira e no mercado. As acompanhantes das duas casas são mulheres, portanto, supôs-se que essas diferenças na organização das casas e ofertas de empréstimo do poder contratual estão conectadas a esses papéis sociais ligados aos corpos femininos e masculinos dos envolvidos, o que indica que essa é uma das instituições presente no cotidiano dos moradores.

Franca Ongaro escreveu sobre a relação entre a loucura e como é vivida socialmente a diferença natural dos corpos feminino e masculino, sujeitos a diferentes níveis de opressão nos espaços públicos e privados. As regras de comportamento feminino se referem ao espaço privado, à casa, e os papéis sociais possíveis são aqueles assumidos na família, carregados de valores morais. As regras de comportamento masculino se referem, principalmente, ao homem como ser social, suas ações, suas relações no mundo, sua maneira de se apresentar e participar, na rua, do jogo social (Ongaro \& Kanoussi, 1985).

Neste estudo, pôde-se constatar que quando em liberdade, os participantes deixaram de ser pessoas reduzidas a um corpo doente, e outras circunstâncias desse corpo entraram na cena. Ser um corpo feminino ou masculino, tanto para os moradores como para as trabalhadoras da casa, parece ser um fator que poderá determinar, limitar ou pressionar para que papéis socialmente estabelecidos sejam desempenhados, nos espaços públicos, a rua, e no espaço privado, a casa.

Um SRT é, ao mesmo tempo, serviço de saúde e casa. Os serviços domésticos são práticas cotidianas utilizadas como recursos para a reabilitação psicossocial, como mostram estudos sobre o cotidiano dos moradores de SRT (Fassheber \& Vidal, 2007; Freire \& Cabral, 2016; Furtado et al., 2010; Generoso \& Guerra, 2012; Kantorki, Cortes, Guedes, Franchini, \& Demarco, 2014; Marcos, 2004). 
Concluiu-se que a análise das práticas cotidianas contribui para a identificação das circunstâncias e construções sociais presentes nas cenas. Cuidar em liberdade exige atenção e mediação para que não haja a substituição por outro único papel fixo predeterminado socialmente. Faz-se necessário observar o que é conectado ao desejo de cada um e o que está sendo instituído pelo outro para que o caminho não seja padronizado, institucionalizado. Caso contrário, o trabalho continuará sendo de apropriar, tornar adequado e conveniente para a convivência social.

\section{A vivificação do "nós": Um mundo em construção}

Na revisão da literatura sobre artigos a respeito do tema do processo de trabalho em serviços residenciais terapêuticos, os principais obstáculos apontados foram a insegurança e falta de preparo dos profissionais (Furtado, 2006; Mângia \& Ricci, 2011; Martins, Moraes, Santos, Peres, \& Almeida Filho, 2012; Moreira \& Castro-Silva, 2011; Pereira \& Borenstein, 2004; Silva \& Azevedo, 2011) e o medo e a resistência da vizinhança (Argiles, Kantorski, Willrich, Antonacci, \& Coimbra, 2013; Freire \& Cabral, 2016; Kantorki et al, 2014; Martins, Peres, Oliveira, Stipp, \& Almeida Filho, 2013; Matos \& Moreira, 2013; Pereira \& Borenstein, 2004; Ribeiro Neto \& Avellar, 2009).

Este estudo indica que a inovação e a variação nas maneiras de realizar o cuidado em liberdade são desafiadoras. Na perspectiva do construcionismo social, o conhecimento é construído na interação social, no encontro, na relação (Gergen \& Gergen, 2010). Observou-se que os moradores estabelecem relações com diferentes atores: profissionais de saúde (acompanhante terapêutica, técnica de enfermagem do Caps, administrativa da recepção da UBS, professora do Mova), moradores do bairro (vizinhas, frequentadores da feira, do supermercado, da igreja, da UBS, do Caps), familiares e prestadores de serviços (funcionário da Pinacoteca, feirante, caixa do supermercado, cobrador de ônibus, ambulante).

Tendo em vista que a real desmontagem do manicômio acontece por meio da participação social, em busca da horizontalidade de poder, fortalecimento comunitário e protagonismo nos espaços de negociação (Amarante \& Torre, 2018; Basaglia, 2010), entendeu-se que as práticas narrativas podem potencializar a incorporação, em um processo de vivificação do "nós". As conversações de reautoria são práticas narrativas que consideram que ao narrar uma história de vida, os fatos que refletem perdas, fracassos, incompetência e sofrimento são privilegiados. Então, elas convidam as pessoas a recontarem suas histórias de vida, incluindo experiências negligenciadas, porém potencialmente significativas, que ficaram em desvantagem em relação às histórias dominantes (White, 2012).

As histórias dominantes de pessoas que passaram por longos períodos de internação são os sintomas, medicações em uso, período de internação. Se os diferentes atores que convivem com os moradores, profissionais de saúde ou não, pudessem ser interlocutores em uma conversação de reautoria, acredita-se que, ao saber das histórias das pessoas para além da descrição da doença, se abriria uma possibilidade de conexão entre eles. Aposta-se que as conversações de reautoria possam ajudar na construção das necessidades de cuidado e planejamento de novos rumos.

O cuidado em liberdade na vivência destes moradores demonstra que a vivificação do "eu" é possível e é vivenciada como um caminho entre a expropriação de si, que ora demanda o empréstimo do poder contratual (dos trabalhadores envolvidos) para apropriação, ora para reapropriação, ora para incorporação. Entre um mundo construído e um mundo em construção, faz-se necessário desvelar outras vozes amparadas em construções sociais que se relacionam com esses corpos.

\section{Considerações finais}

Para o agenciamento social da loucura, faz-se minimamente necessário uma Raps que não opere como um circuito de controle, ou seja, que não se reduza a um conjunto de instituições que reproduzem uma lógica de normalização impositiva e geram exclusão social (Basaglia, 2010). No cenário brasileiro, em 1987, foi lançado para a sociedade o desafio de viver sem manicômios. Em 2017, completaram-se 30 anos de luta antimanicomial no Brasil, período em que ocorreram transformações importantes. Dessa vez, em um encontro nacional com representantes dos diferentes atores sociais, as pessoas que utilizam os serviços estavam presentes. Parte do desafio lançado foi alcançada com a garantia da presença de pessoas, antes excluídas, circulando pelas cidades e falando por si.

Dentre os debates sobre as conquistas nesses 30 anos, estavam também em discussão as diretrizes para a Política de Saúde Mental propostas pelo Ministério da Saúde, aprovadas em 14 de dezembro de 2017, sem a participação do controle social. As regras do financiamento foram alteradas de modo a privilegiar 
as internações psiquiátricas, com mudança da Raps, incluindo ambulatórios e hospitais especializados em psiquiatria. Essas mudanças foram consideradas um retrocesso por serem contrárias ao caminho que era trilhado na Reforma Psiquiátrica Brasileira, sustentado pela desinstitucionalização, e representam grande possibilidade de retorno a um modelo superado. Essa realidade reforça a necessidade de estudos que discutam a repercussão das políticas sociais na vida em sociedade e que apresentem sua conexão com a operacionalização da atenção psicossocial.
Nesse encontro, surgiu uma cena ilustrativa do cuidado em liberdade. Em uma das rodas de conversa, foi possível ouvir de um dos participantes, depois de tanto ser chamado de usuário do serviço, que ele gostaria de ser chamado pelo seu nome. Essa cena contribuiu para todos ali presentes entenderem que pessoas que têm nome, documento, casa etc. têm mais chance de formar parcerias, construir novos rumos e conhecimentos para o cuidado em liberdade, sustentar o protagonismo dos sujeitos e lutar contra os retrocessos e perda de direitos.

\section{Referências}

Amarante, P., \& Torre, E. H. G. (2018). “De volta à cidade, sr. cidadão!” - Reforma psiquiátrica e participação social: Do isolamento institucional ao movimento antimanicomial. Revista de Administração Pública, 52(6), 1090-1107. http://dx.doi.org/10.1590/0034-761220170130

Argiles, C. T. L., Kantorski, L. P., Willrich, J. Q., Antonacci, M. H., \& Coimbra, V. C. C. (2013). Redes de sociabilidade: Construções a partir do serviço residencial terapêutico. Ciência \& Saúde Coletiva, 18(7), 2049-2058. https://dx.doi.org/10.1590/S1413-81232013000700020

Barros, S., \& Bichaff, R. (2008). Desafios para a desinstitucionalização: Censo Psicossocial dos Moradores em Hospitais Psiquiátricos do Estado de São Paulo. Fundap. https:// repositorio.usp.br/item/001763213

Barros, S., Oliveira, M. A. F., \& Silva, A. L. A. (2007). Práticas inovadoras para o cuidado em saúde. Revista da Escola de Enfermagem da USP, 41(Esp), 815-819. https://dx.doi.org/10.1590/S0080-62342007000500013

Basaglia, F. (2010). Escritos selecionados: Em saúde mental e reforma psiquiátrica. Garamond.

Cayres, A. Z. F., Ribeiro, M. A., Elias, R., \& Coutinho, R. A. (2015). Caminhos para a desinstitucionalizaão no Estado de São Paulo: Censo Psicossocial 2014. Fundap. http://www.saude.sp.gov.br/resources/ses/perfil/profissional-da-saude/ grupo-tecnico-de-acoes-estrategicas-gtae/saude-mental/censo-psicossocial/censo_psicossocial_2014.pdf

Certeau, M. D. (1998). A invenção do cotidiano: Artes de fazer (E. F. Alves, Trad., 3a ed.). Vozes.

Certeau, M. D., Giard, L., \& Mayol, P. (2016). A invenção do cotidiano: 2. Morar, cozinhar (E. F. Alves, \& L. M. E. Orth, Trads., 12a ed.). Vozes.

Desviat, M. (1999). A reforma psiquiátrica (V. Ribeiro, Trad., 20a ed.). Fiocruz.

Fassheber, V. B., \&Vidal, C. E. L. (2007). Da tutela à autonomia: Narrativas e construções do cotidiano em uma residência terapêutica. Psicologia: Ciência e Profissão, 27(2), 194-207. https://dx.doi.org/10.1590/S1414-98932007000200003

Ferreira, A. B. H. (2014). Dicionário Aurélio da Língua Portuguesa (5a ed.) Positivo.

Freire, É. V. S., \& Cabral, B. E. B. (2016). Saúde mental no território: Reflexões sobre agenciamentos possíveis na relação coma residência terapêutica. Cadernos Brasileiros de Saúde Mental, 8(19), 17-41.

Furtado, J. P. (2006). Avaliação da situação atual dos Serviços Residenciais Terapêuticos no SUS. Ciência \& Saúde Coletiva, 11(3), 785-95. https://dx.doi.org/10.1590/S1413-81232006000300026

Furtado, J. P., Nakamura, E., Generoso, C. M., Guerra, A. M. C., Campos, F. B. \& Tugny, A. (2010). Inserção social e habitação: Um caminho para a avaliação da situação de moradia de portadores de transtorno mental grave no Brasil. Interface-Comunicação, Saúde, Educação, 14(33), 389-400. https://dx.doi.org/10.1590/ S1414-32832010000200012

Generoso, C. M., \& Guerra, A. M. C. (2012). Desinserção social e habitação: A psicanálise na reforma psiquiátrica brasileira. Revista Latinoamericana de Psicopatologia Fundamental, 15(3), 524-39. https://dx.doi.org/10.1590/ S1415-47142012000300006

Gergen, K. J., \& Gergen, M. (2010). Construcionismo social: Um convite ao diálogo. Instituto NOOS.

Goffman, E. (2015). Manicômios, prisões e conventos (D. M. Leite, Trad., 9a ed.). Perspectivas. 
Honorato, C.E. D. M., \&Pinheiro, R. (2008). O trabalho do profissional de saúdemental em um processo de desinstitucionalização. Physis: Revista de Saúde Coletiva, 18(2), 361-380. https://dx.doi.org/10.1590/S0103-73312008000200009

Kantorki, L. P., Cortes, J. M., Guedes, A. C., Franchini, B., \& Demarco, D. A. (2014). O cotidiano e o viver no Serviço Residencial Terapêutico. Revista Eletrônica de Enfermagem, 16(4), 759-768. https://doi.org/10.5216/ree.v16i4.22923

Kinoshita, R. T. (2001). Contratualidade e reabilitação psicossocial. In A. Pitta (Org.), Reabilitação psicossocial no Brasil (2a ed, pp. 55-59). Hucitec.

Lago, E. A., Machado, R. S., Vieira, T. S., \& Monteiro, C. F. S. (2014). Perfil de moradores de serviços residenciais terapêuticos. Revista de Enfermagem da UFPI, 3(1), 10-17. https:/ / doi.org/10.26694/reufpi.v3i1.1113

Lei no 10.216, de 6 de abril de 2001. (2001, 9 de abril). Dispõe sobre a proteção e os direitos das pessoas portadoras de transtornos mentais e redireciona o modelo assistencial em saúde mental. Diário Oficial da União. http:// www.planalto.gov.br/ccivil_03/leis/leis_2001/l10216.htm

Magnani, J. G. C. (2009). Etnografia como prática e experiência. Horizontes antropológicos, 15(32), 129-156. https://dx.doi.org/10.1590/S0104-71832009000200006

Mângia, E. F., \& Ricci, E. C. (2011). "Pensando o Habitar” Trajetórias de usuários de Serviços Residenciais Terapêuticos. Revista de Terapia Ocupacional da Universidade de São Paulo, 22(2), 182-190. https://doi.org/10.11606/ issn.2238-6149.v22i2p182-190

Marcos, C. M. (2004). A reinvenção do coditiano e a clínica possível nos "Serviços Residenciais Terapêuticos". Psychê, 8(14), 179-190.

Martins, G. C. S., Moraes. A. E. C., Santos, T. C. F, Peres, M. A. A., \& Almeida Filho, A. J. (2012). O processo de implantação de residências terapêuticas em Volta Redonda - Rio de Janeiro. Texto \& Contexto Enfermagem, 21(1), 86-94. https://dx.doi.org/10.1590/S0104-07072012000100010

Martins G. C. S., Peres M. A. A., Oliveira, A. M. B., Stipp, M. A. C., \& Almeida Filho, A. J. (2013). O estigma da doença mental e as residências terapêuticas no município de Volta Redonda-RJ. Texto \& Contexto Enfermagem, 22(2), 327-34. https://dx.doi.org/10.1590/S0104-07072013000200008

Matos, B. G. D., \& Moreira, L. H. D. O. (2013). Servico residencial terapeutico: O olhar do usuario. Escola Anna Nery Revista Enfermagem, 17(4), 668-676. https://dx.doi.org/10.5935/1414-8145.20130010

Minayo, M. C. S. (2008). Introdução à metodologia de Pesquisa Social. In M. C. S. Minayo, O desafio do conhecimento: Pesquisa qualitativa em saúde (9a ed., pp. 21-88). Hucitec.

Ministéio da Saúde. (2017). Panorama e diagnóstico da Política Nacional de Saúde Mental. http://portalarquivos2. saude.gov.br/images/pdf/2017/setembro/04/2a-Apresentacao-CIT-Final.pdf

Ministério da Saúde. (2016). Saúde Mental no SUS: Cuidado em liberdade, defesa de direitos e Rede de Atenção Psicossocial. Relatório de Gestão 2011-2015. http://portalarquivos2.saude.gov.br/images/pdf/2016/junho/27/ Relat--rio-Gest--o-2011-2015---.pdf

Moreira, M. I. B., \& Andrade, A. N. (2007). Habitar a cidade: Análise de serviços residenciais terapêuticos. Psicologia e Sociedade, 19(3), 46-54. https://doi.org/10.1590/S0102-71822007000300008

Moreira, M. I. B., \& Andrade, A. N. (2010). Viver em liberdade: Investidas no bairro e convívio com os vizinhos. In F. B. Campos, \& A. Lancetti (Orgs.), SaudeLoucura 9: Experiências da Reforma Psiquiátrica (pp. 353-370). Hucitec.

Moreira, M. I. B., \& Castro-Silva, C. R. (2011). Residências terapêuticas e comunidade:A construção de novas práticas antimanicomiais. Psicologia \& Sociedade, 23(3), 545-553. https://dx.doi.org/10.1590/S0102-71822011000300012

Nicácio, M. F. D. S. (2003). Utopia da realidade: Contribuições da desinstitucionalização para a invenção de serviços de saúde mental [Tese de doutorado, Universidade Estadual de Campinas]. Repositório da Produção Científica e Intelectual da Unicamp. http://repositorio.unicamp.br/jspui/handle/REPOSIP/311999

Ongaro, F. B, \& Kanoussi, D. (1985). Mujer, locura y sociedad (A. M. Magaldi, \& C. Kielack, Trads., 2a ed.). Universidad Autónoma de Puebla. https://antipsiquiatriaudg.files.wordpress.com/2015/08/basaglia-franca-mujer-locura-y-sociedad.pdf

Paulon, S., Resende, V., Knijinik, C., Oliveira, E., \& Abreu, M. (2007). Das múltiplas formas de habitar uma morada: A produção do cuidado em um serviço residencial terapêutico. Vivência: Revista de Antropologia, 32, 119-117. 
Pereira, V. P., \& Borenstein, M. S. (2004). Iluminando as vivências de mulheres portadoras de transtornos psíquicos e moradoras de uma residência terapêutica. Texto \& contexto enfermagem, 13(4), 527-534. https:// dx.doi.org/10.1590/S0104-07072004000400004

Pitta, A. M. F. (2011). Um balanço da reforma psiquiátrica brasileira: Instituições, atores e políticas. Ciência \& saúde coletiva, 16(12), 4579-4589. https://doi.org/10.1590/S1413-81232011001300002

Portaria n. 106, de 11 de fevereiro de 2000. (2000, 24 de fevereiro). Dispõe sobre a criação e regulamentação das residências terapêuticas para portadores de transtornos mentais. Diário Oficial da União. http:// portalarquivos2.saude.gov.br/images/pdf/2015/marco/10/PORTARIA-106-11-FEVEREIRO-2000.pdf

Portaria n. 3088, de 23 de dezembro de 2011 (2013, 20 de maio). Institui a Rede de Atenção Psicossocial para pessoas com sofrimento ou transtorno mental e com necessidades decorrentes do uso de crack, álcool, e outras drogas no âmbito do Sistema Único de Saúde (SUS). Diário Oficial da União. http://bvsms.saude.gov.br/bvs/ saudelegis/gm/2011/prt3088_23_12_2011_rep.html

Ribeiro Neto, P. M., \& Avellar, L. Z. (2009). Conhecendo os cuidadores de um serviço residencial terapêutico. Mental, 7(13).

Rotelli, F., \& Nicácio, F. (2001). A instituição inventada. In F. Rotelli, O. de Leonardis, \& D. Mauri, Desinstitucionalização (2a ed., pp. 89-99). Hucitec.

Santos Junior, H. P. O., \& Silveira, M. F. A. (2009). Práticas de cuidados produzidas no serviço de residências terapêuticas: Percorrendo os trilhos de retorno à sociedade. Revista da Escola de Enfermagem da USP, 43(4), 788-795. https://dx.doi.org/10.1590/S0080-62342009000400008

Schmidt, B. B. (1994). Práticas e táticas: Michel de Certeau (re)inventa o cotidiano. Biblos, 6, 79-93. https:// www.seer.furg.br/biblos/article/view/337

Secretaria Municipal de Saúde de São Bernardo do Campo. (2012). Saúde Mental - tratamento aberto com respeito à cidadania: Rede de equipamentos foi ampliada, oferecendo conforto e acolhimento humanizado. Cadernos da Saúde SBC, 2.

Silva, D. S., \& Azevedo, D. M. (2011). A reforma psiquiátrica na visão de quem cuida: Percepções de profissionais do serviço residencial terapêutico. Escola Anna Nery Revista de Enfermagem, 15(3), 587-94. https:// dx.doi.org/10.1590/S1414-81452011000300021

Spink, M. J. P. (2007). Pesquisando no cotidiano: Recuperando memórias de pesquisa em Psicologia Social. Psicologia \& Sociedade, 19(1), 7-14. https://dx.doi.org/10.1590/S0102-71822007000100002

Sztajnberg, T. K., \& Cavalcanti, M. T. (2010). A arte de morar... na Lua: A construção de um novo espaço de morar frente à mudança do dispositivo asilar para o Serviço Residencial Terapêutico. Revista Latinoamericana de Psicopatologia Fundamental, 13(3), 457-468. https:// dx.doi.org/10.1590/S1415-47142010000300006

Tenório F. (2002). A reforma psiquiátrica brasileira, da década de 1980 aos dias atuais: História e conceitos. História, Ciências, Saúde-Manguinhos, 9(1), 25-59. https://dx.doi.org/10.1590/S0104-59702002000100003

Vasconcelos, E. M. (2012). Crise mundial, conjuntura política e social no Brasil, e os novos impasses teóricos na análise da reforma psiquiátrica no país. Cadernos Brasileiros de Saúde Mental, 4(8), 8-21.

Vaz, B. C., Silva, E. A., \& Campos, F. C. B. (2014). Ver, ouvir e falar: As estratégias utilizadas no trabalho de campo. In J. P. Furtado, \& E. Nakamura (Orgs.), Inserção social e habitação de pessoas com sofrimento mental grave (pp. 221-238). FAP/Unifesp.

Wachs, F., Jardim, C., Paulon, S. M., \& Resende, V. (2010) Processos de subjetivação e territórios de vida: O trabalho de transição do hospital psiquiátrico para os serviços residenciais. Physis: Revista de Saúde Coletiva, 20(3), 895912. https://dx.doi.org/10.1590/S0103-73312010000300011

White, M. (2012). Conversações de reautoria (A. Migliavaca, Trad.). In M. White, Mapas da prática narrativa (pp. 75-144). Pacartes.

Paula Andréa Massa

Doutoranda em Ciências pelo Programa Interdisciplinar em Ciências da Saúde. Universidade Federal de São Paulo 
(Unifesp), Santos - SP. Brasil.

E-mail: paulamassa81@gmail.com

(1) https://orcid.org/0000-0002-8807-421X

\section{Maria Inês Badaró Moreira}

Doutora em Psicologia. Professora do Departamento de Políticas Públicas e Saúde Coletiva da Unifesp, Santos - SP. Brasil.

E-mail: mibadaro@gmail.com

(1) https://orcid.org/0000-0001-5798-2023

Endereço para envio de correspondência:

Universidade Federal de São Paulo (Unifesp). Rua Silva Jardim, 136, Vila Mathias. CEP: 11015-000. Santos - SP. Brasil.

Recebido 02/06/2018

Aceito 19/03/2019

Received 06/02/2018

Approved 03/19/2019

Recibido 02/06/2018

Aceptado 19/03/2019

Como citar: Massa, P. A., \& Moreira, M. I. B. (2021). Na casa e na rua: Cenas dos moradores de serviços residenciais terapêuticos. Psicologia: Ciência e Profissão, 41 (n.spe 4), 1-13. https://doi.org/10.1590/1982-3703003201933

How to cite: Massa, P. A., \& Moreira, M. I. B. (2021). In the house and in the street: Therapeutic Residential Services Resident's scenes. Psicologia: Ciência e Profissão, 41 (n.spe 4), 1-13. https://doi.org/10.1590/1982-3703003201933

Cómo citar: Massa, P. A., \& Moreira, M. I. B. (2021). En la casa y en la calle: Escenas de los residentes de Servicios Residenciales Terapéuticos. Psicologia: Ciência e Profissão, 41 (n.spe 4), 1-13.

https://doi.org/10.1590/1982-3703003201933 